\title{
HISTOCHEMICAL LOCALIZATION OF GLYCOGEN IN PREIMPLANTATION AND IMPLANTATION STAGES OF YOUNG AND SENESCENT GOLDEN HAMSTERS
}

\author{
T. A. PARKENING* AND A. L. SODERWALL \\ Department of Biology, University of Oregon, Eugene, Oregon 97403, U.S.A.
}

(Received 22nd January 1974)

\begin{abstract}
Summary. Eggs obtained from young and senescent golden hamsters at $\frac{1}{2}$ to $3 \frac{1}{2}$ days of pregnancy were tested for glycogen using the PAS technique. The staining intensity was greatest in one-cell embryos, and decreased with subsequent cellular divisions up to the late blastocyst stage. Zygotes examined from senescent animals after 2 days of pregnancy consistently exhibited a developmental stage approximately $12 \mathrm{hr}$ earlier than embryos obtained from younger animals. Microphotometric measurements of PAS-stained blastocysts at comparable stages from young and senescent animals revealed no statistical difference in glycogen content.

Embryos from young and senescent hamsters embedded in situ in glycol methacrylate were examined for glycogen using the PAS technique at $3 \frac{1}{2}$ to $5 \frac{1}{2}$ days of pregnancy. Glycogen in most older animals from 4 to 5 days of pregnancy paralleled that found in younger animals $12 \mathrm{hr}$ earlier. At $5 \frac{1}{2}$ days, glycogen deposits surrounding implantations in senescent uteri were less than those found in younger uteri at 5 days of pregnancy. A few implantations from senescent females at this stage of pregnancy were completely devoid of glycogen, except for deposits in the myometrium. The smaller quantities of stored uterine glycogen and a reduced uterine circulation may be responsible for the increased fetal resorptions noted in senescent hamsters at later stages of gestation.
\end{abstract}

\section{INTRODUCTION}

The presence of glycogen has been demonstrated histochemically using the periodic acid-Schiff (PAS) technique in preimplantation stages of the mouse (Thomson \& Brinster, 1966) and hamster (McReynolds \& Hadek, 1972) and during implantation in the mouse (Smith, 1966; Wong \& Dickson, 1969; Smith \& Wilson, 1971), hamster (Connors, 1969), rat (Christie, 1966) and rabbit (Christie, 1967).

The female golden hamster exhibits a significant decline in litter size after 14 months of age (Soderwall, Kent, Turbyfill \& Britenbaker, 1960); the greatest embryonic mortality occurring before $5 \frac{1}{2}$ days of pregnancy (Connors, Thorpe

* Present address: Worcester Foundation for Experimental Biology, Shrewsbury, Massachusetts 01545, U.S.A. 
\& Soderwall, 1972). A developmental delay of approximately $12 \mathrm{hr}$ has been noted in senescent hamsters examined before and during implantation (Connors, 1969; Parkening \& Soderwall, 1973a, b). Since the time of ovulation from the onset of behavioural oestrus is similar in young and senescent hamsters (Stockton, 1972), this study was conducted to determine whether overutilization of glycogen by retarded blastocysts of senescent animals was a limiting factor in successful implantation.

\section{MATERIALS AND METHODS}

Golden hamsters (Mesocricetus auratus), housed individually under constant conditions of temperature $\left(21\right.$ to $23^{\circ} \mathrm{C}$ ) and lighting $(20.00$ to 08.00 hours dark), were examined daily for the vaginal discharge to check the occurrence of normal 4-day oestrous cycles. Young nulliparous (3 to 5 months) and senescent multiparous ( 14 to 17 months) females exhibiting three to five normal oestrous cycles were placed with males ( 3 to 6 months) of proven fertility and observed for the onset of lordosis and copulation. Developmental age was determined from the time of ovulation, considered to be $8 \mathrm{hr}$ from the onset of behavioural oestrus (Harvey, Yanagimachi \& Chang, 1961). Three to six young or senescent hamsters were killed at each time period.

Preimplantation stages were obtained from hamsters after $\frac{1}{2}, 1,2,2 \frac{1}{2}, 3$, $3 \frac{1}{6}$ and $3 \frac{1}{2}$ days of pregnancy. Ova obtained by mincing oviducts or flushing uterine horns were prepared, fixed and histochemically stained for glycogen, using the PAS technique of Thomson \& Brinster (1966). Control ova were incubated in $1.0 \%$ aqueous malt diastase for $1 \mathrm{hr}$ at $37^{\circ} \mathrm{C}$ before staining.

The relative dye concentration of the ova was determined by using a Reichert microphotometer. A two-wavelength method was employed (Swift \& Rasch, 1956), using $480 \mathrm{~nm}$ and $550 \mathrm{~nm}$ wavelengths, to measure whole ova for a quantitative estimate of their glycogen content based on the absorptivity or staining intensity of the PAS reaction. The wavelengths were chosen through a standard absorption curve on several stained blastocysts. Microphotometric measurements were statistically compared using Student's $t$ test (Sokal \& Rohlf, 1969).

Implantation stages were obtained from hamsters at $3 \frac{1}{2}, 4,4 \frac{1}{2}, 5$ and $5 \frac{1}{2}$ days after ovulation. The animals were anaesthetized and $0.25 \mathrm{ml}$ of pontamine blue was injected into the femoral vein for the detection of implantation sites (Orsini, 1963) 15 min before perfusion with $2.5 \%$ phosphate-buffered glutaraldehyde at $4^{\circ} \mathrm{C}$ through the abdominal aorta. The implantations indicated by pontamine blue were counted and the intensity of the dye recorded as: negative $(-)$, faintly positive $(t)$, moderately positive $(+t)$, strongly positive $(+++)$. Implantation sites were dissected out (or the entire uterus was removed if sites were not visible), sectioned into smaller pieces, and fixed for an additional $1 \frac{1}{2} \mathrm{hr}$. The tissues were dehydrated through an ethanol series and embedded in paraffin wax or butoxyethanol-glycol methacrylate (Ruddell, 1967). Sections ( $\frac{1}{2}$ to $1 \mu \mathrm{m}$ ) of methacrylate-embedded uteri were treated with the aldehyde-blocking agents, dimedone (Bulmer, 1959) for $3 \mathrm{hr}$ at $60^{\circ} \mathrm{C}$ or 2,4-dinitrophenylhydrazine (Feder \& O'Brien, 1968) for $10 \mathrm{~min}$, 


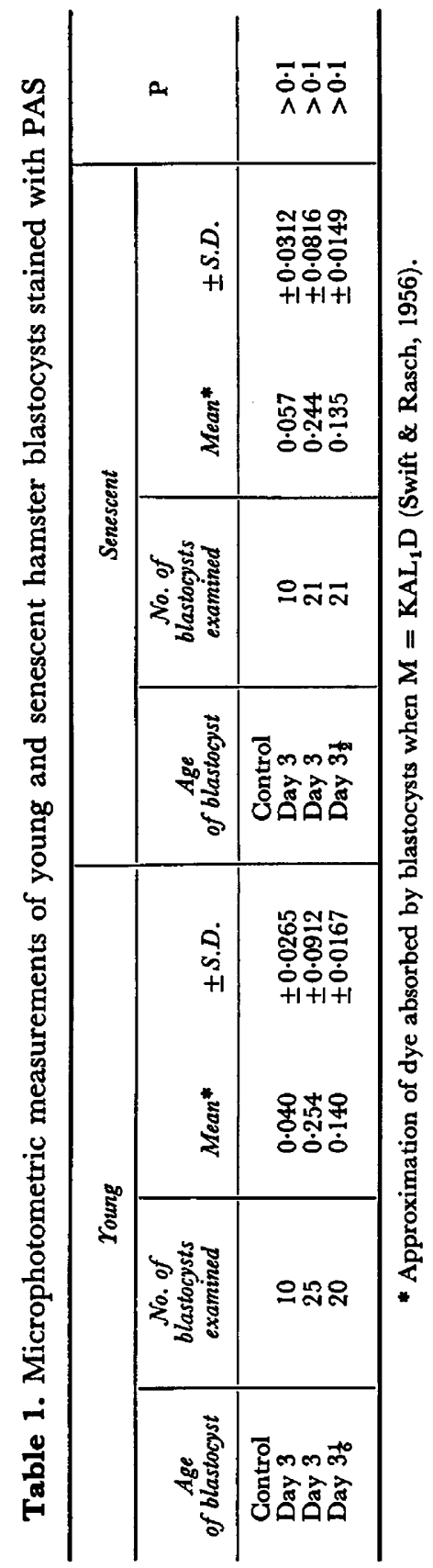




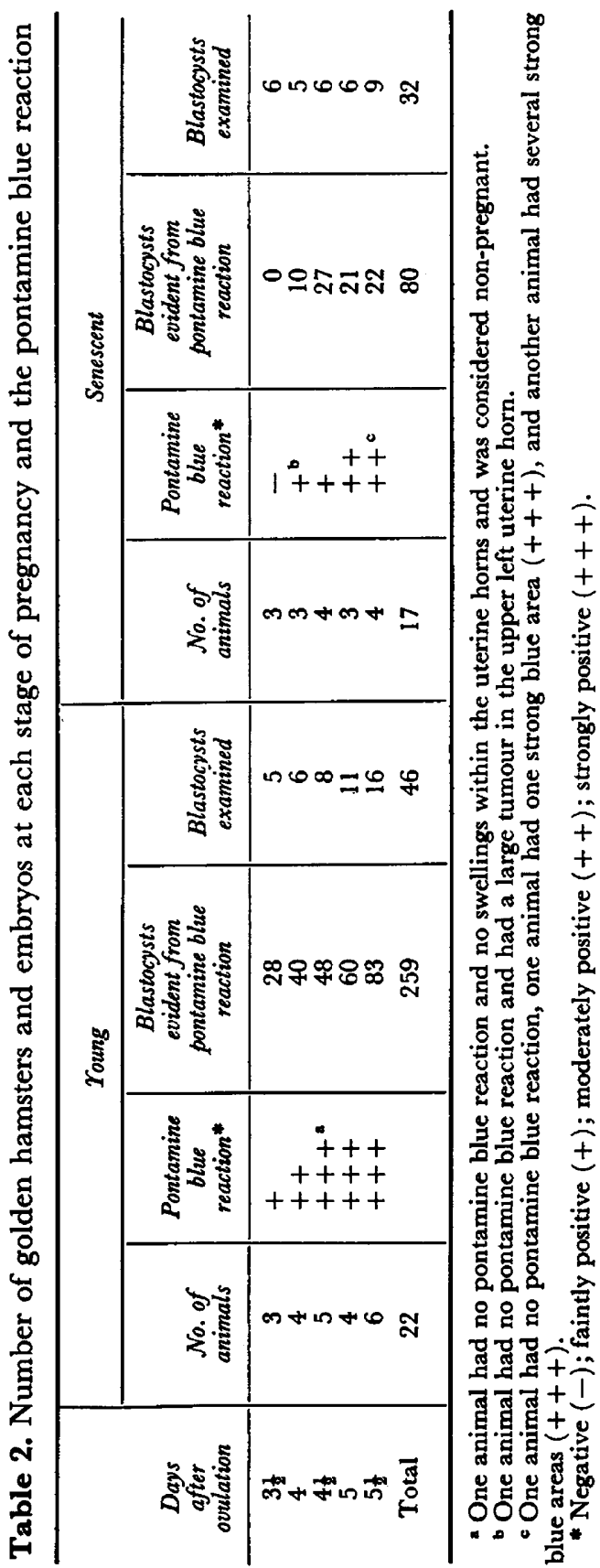


before staining with the PAS technique of McManus as described by Pearse (1968). Paraffin wax-embedded sections $(5 \mu \mathrm{m})$, serving as controls, were treated in the same manner after incubation for $2 \mathrm{hr}$ at $37^{\circ} \mathrm{C}$ in $1.0 \%$ aqueous malt diastase.

\section{RESULTS}

Preimplantation stages from young and senescent hamsters exhibited a similar PAS-positive reaction which was digestible in diastase and presumed to be glycogen. The strongest staining reaction occurred at the one-cell stage (Pl. 1, Fig. 1) and gradually decreased in intensity to the late blastocyst stage (Pl. 1, Figs 2 to 11). Blastocysts which remained intact could not be readily obtained by flushing the uterine horns of young females at $3 \frac{1}{2}$ days of pregnancy. Those blastocysts which were obtained intact had already lost the zona pellucida. Since blastocysts were already surrounded by the uterine epithelium at this stage of pregnancy, young hamsters were killed 3 days and $4 \mathrm{hr}$ after ovulation. Many blastocysts obtained at this time retained their zonae pellucidae and were developmentally similar to the blastocysts acquired from senescent animals at $3 \frac{1}{2}$ days of pregnancy. Although the PAS reaction became extremely faint in the late stages of young and senescent blastocysts, it was never completely absent when these stages were compared with comparable controls.

The microphotometric estimate of the intensity of the PAS reaction revealed no significant differences $(P>0 \cdot 1)$ between blastocysts of young and senescent animals (Table 1). The concentration of the reaction was too intense for accurate measurement before the blastocyst stage.

Preimplantation embryos from senescent hamsters were noticeably delayed in their development when compared with embryos of young animals by Day 2 of pregnancy (Pl. 1, Figs 1 to 11 ). All embryos obtained from young animals at this age were in the four-cell stage, while more than $50 \%$ of the senescent embryos were still in the two-cell and three-cell stage. This pattern of development continued and became more pronounced as pregnancy progressed, with the embryos of senescent animals consistently at a stage of development found in younger animals $12 \mathrm{hr}$ earlier. Before Day 2 of pregnancy, an obvious developmental delay in senescent embryos was not apparent.

The number of non-viable ova (Pl. 1, Fig. 12) recovered from senescent animals before implantation was much greater than the number found in younger animals. From twenty-one senescent hamsters, 242 ova were recovered, of which $23.1 \%$ were non-viable (fourteen abnormal, forty-two degenerating). In twenty-four young hamsters, only $2 \cdot 1 \%$ of the 292 ova recovered were non-viable (three abnormal, three degenerating).

The pontamine blue reaction was initially delayed in senescent animals for $12 \mathrm{hr}$ (Table 2), e.g. where blue areas were visible in the uterine horns of young hamsters at $3 \frac{1}{2}$ days of pregnancy, they did not occur until 4 days of pregnancy in older animals. The subsequent intensity of the dye was delayed approximately 12 to $24 \mathrm{hr}$ in senescent females when compared with younger females throughout each stage of pregnancy. The number of implantation sites indicated by pontamine blue between Days 4 and $5 \frac{1}{2}$ of pregnancy was 231 in the 
young hamsters and eighty in the older ones, but some of the implantations may have failed to respond to the pontamine blue.

In young hamsters, small dispersed areas of glycogen were found throughout $3 \frac{1}{2}$-day embryos embedded in situ in glycol methacrylate (Pl. 2, Fig. 13). During this time, glycogen was not detectable in the epithelial cells, decidual cells (which were just beginning to form antimesometrially) or the stromal cells. All of the embryos from young animals were tightly enclosed by uterine epithelium at this stage of pregnancy. At Day 4 in younger animals, small granules of glycogen were just detectable in decidual cells adjacent to the embryo antimesometrially. Glycogen was deposited in the primary decidua at Day $4 \frac{1}{2}$ and was spreading around the implanting embryos (P1. 2, Fig. 17). Some embryos at this stage accumulated rather dense deposits of glycogen at the embryonic pole where cells would eventually differentiate into the ectoplacental cone. On Day 5, some embryos from young females were completely surrounded with dense deposits of glycogen although it was beginning to disappear from decidual cells immediately adjacent to the embryo (Pl. 3, Fig. 20). Glycogen first became absent at the antimesometrial end of the embryo and proceeded to disappear laterally. At $5 \frac{1}{2}$ days, only a band of glycogen some distance from the implantation site encompassed the embryo (Pl. 3, Figs 23 and 24).

All the blastocysts from senescent hamsters at $3 \frac{1}{2}$ days of pregnancy had retained the zona pellucida and were free within the uterine lumen. The distribution of glycogen within the trophoblast and inner cell mass was similar to that of the blastocyst enclosed by uterine epithelium in young animals. At Days 4, $4 \frac{1}{2}$ and 5 (Pl. 2, Figs 14 to 16, and Pl. 3, Fig. 19), the glycogen distribution within the embryo and surrounding decidual cells paralleled that found in young hamsters at Days $3 \frac{1}{2}, 4$ and $4 \frac{1}{2}$. The quantity of glycogen in ageing uteri also appeared visually similar in most implants to that in younger uteri $12 \mathrm{hr}$ earlier. At $5 \frac{1}{2}$ days of pregnancy, aged hamsters did not follow the same trend previously described. Although the embryo and decidua were developmentally similar to that in young animals at Day 5 , the concentration

\section{EXPLANATION OF PLATE 1}

All embryos were whole mounts stained with the periodic acid-Schiff technique.

Fig. 1. Fertilized zygote from a young hamster $12 \mathrm{hr}$ after ovulation. The male and female pronuclei are visible in the centre of the ovum. $\times 890$.

Fig. 2. Two-cell embryo from a senescent hamster at 2 days of pregnancy. $\times 890$.

FIG. 3. Two-cell embryo from a $1 \frac{1}{2}$-day pregnant senescent hamster. The zona pellucida was not dissolved away by the acetic acid of the fixation solution as in the other embryos. $\times 360$.

Fig. 4. Three-cell embryo from a senescent hamster at $2 \frac{1}{2}$ days of pregnancy. $\times 890$.

FIG. 5. Four-cell embryo from a young hamster at 2 days of pregnancy. $\times 890$.

Fig. 6. Eight-cell embryo from a $2 \frac{1}{2}$-day pregnant senescent hamster. $\times 890$.

Fig. 7. Ten-cell embryo from a young hamster at $2 \frac{1}{2}$ days of pregnancy. $\times 890$.

Fig. 8. Early blastocyst from a 3-day pregnant senescent hamster. $\times 890$.

FIG. 9. Late blastocyst recovered from a young hamster after $3 \frac{1}{6}$ days of pregnancy. $\times 890$.

Fig. 10. Late blastocyst from a $3 \frac{1}{6}$-day pregnant young hamster. $\times 890$.

Fig. 11. Late blastocyst from a senescent hamster at $3 \frac{1}{2}$ days of pregnancy. $\times 890$.

Fig. 12. Three degenerating ova from a senescent hamster pregnant for $3 \frac{1}{2}$ days. $\times 890$. 
PLATE 1
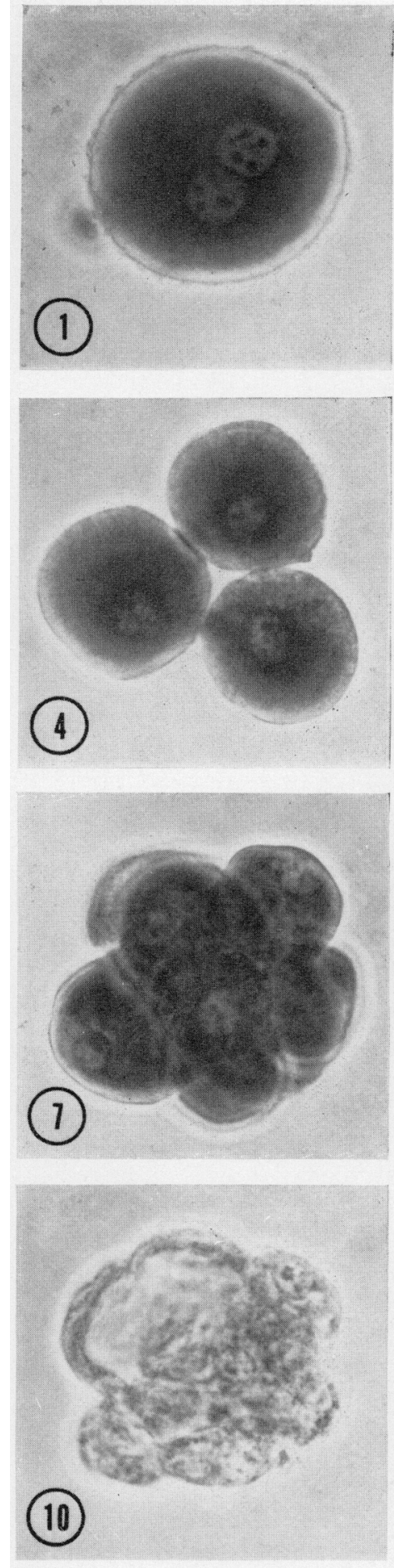
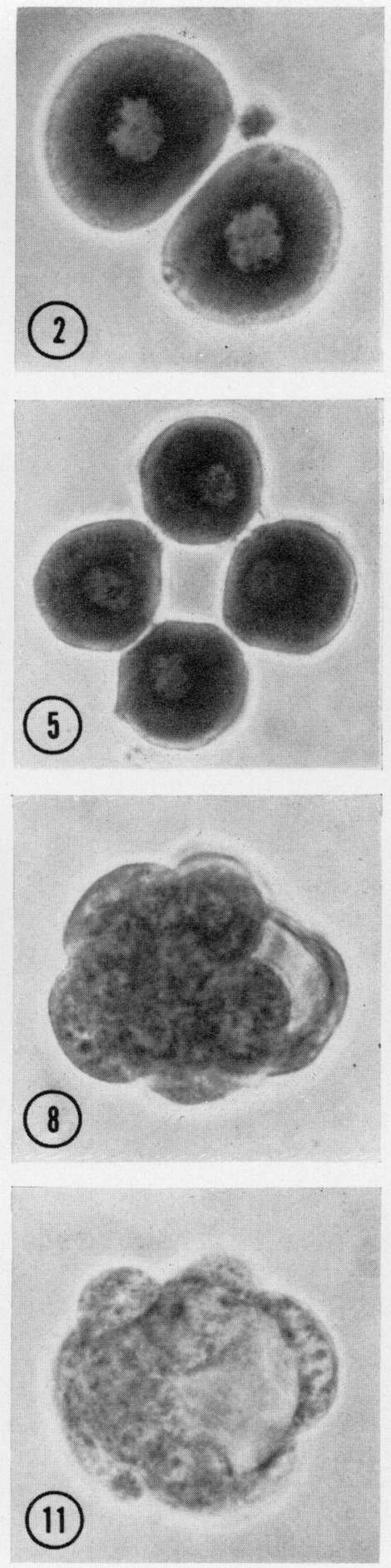

(3)
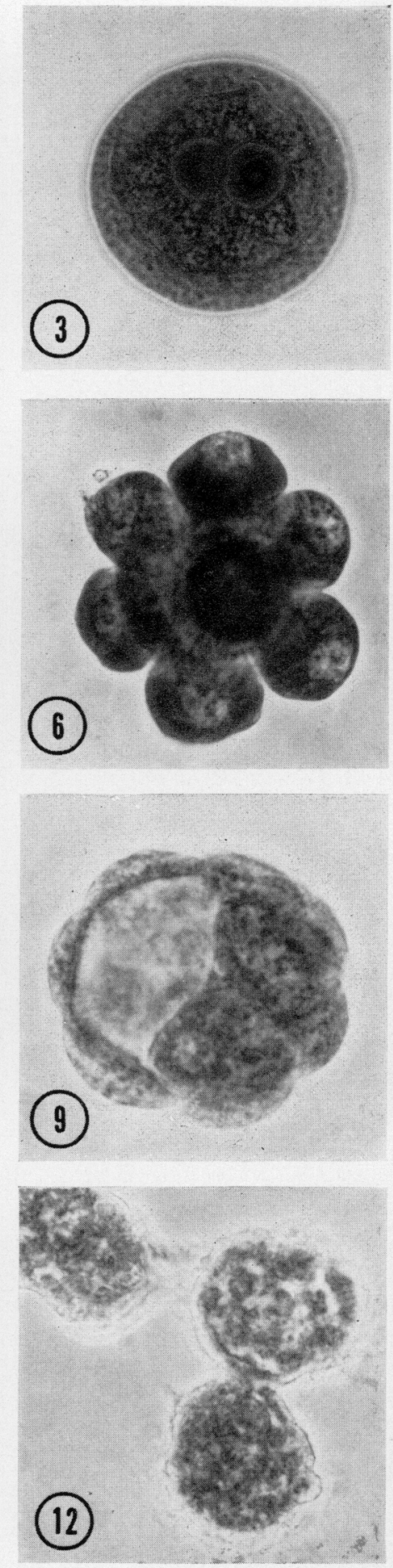

(Facing p. 290) 

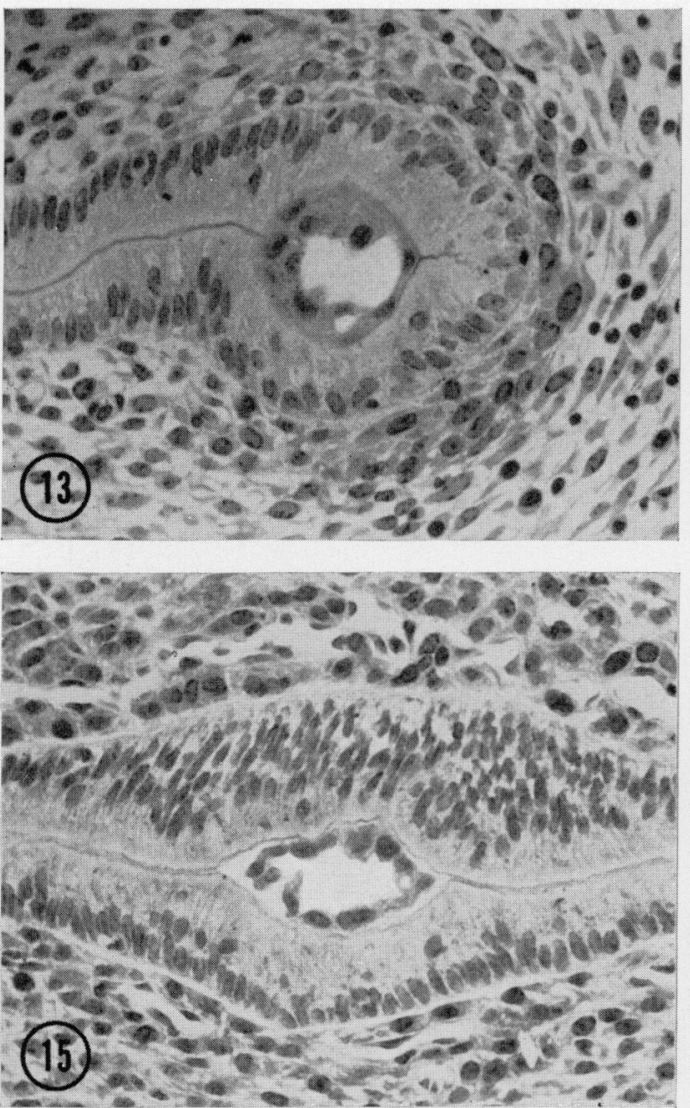

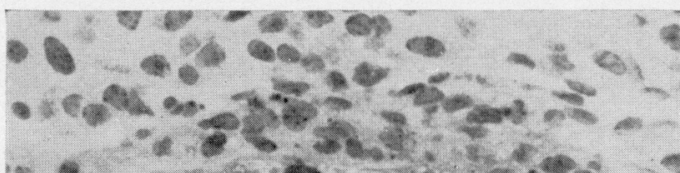

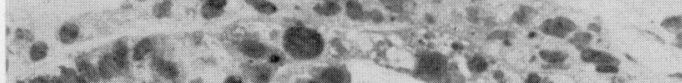

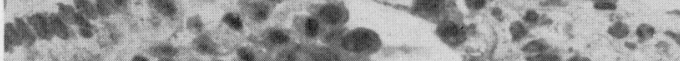

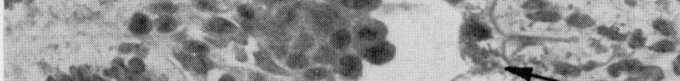

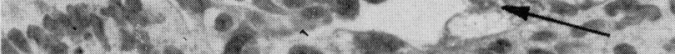
$\cos$.

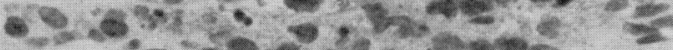

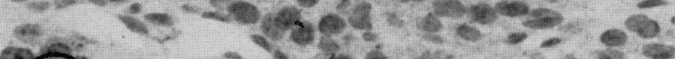

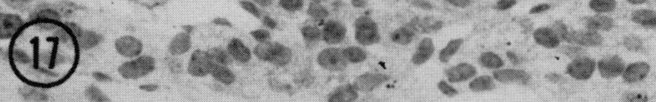
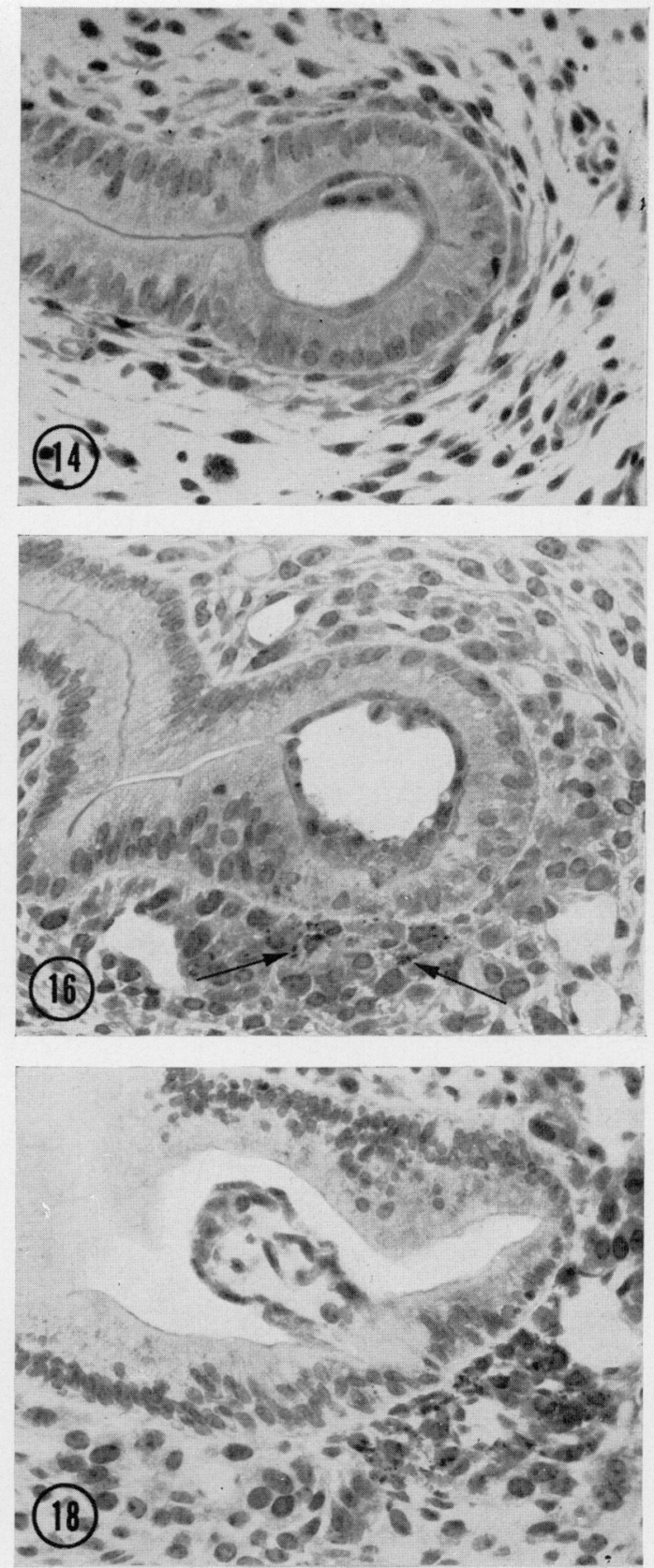
of glycogen in the decidual cells of all embryos examined was noticeably less (Pl. 3, Fig. 21). No glycogen was found within the embryo or endometrium (Pl. 3, Fig. 22) in four apparently normal embryos at this stage (three acquired from the same senescent animal) even though deposits of glycogen in the longitudinal and circular muscles were similar to those noted in young and senescent uteri. Two of the embryos, however, had some blood lacunae directly adjacent to the implantation but few lacunae in the decidua (Pl. 3, Fig. 22).

All of the embryos from young females examined from plastic-embedded tissues appeared normal in their development while two embryos from senescent females, both at 5 days of pregnancy, were abnormal. One of the embryos was in a state of degeneration (Pl. 2, Fig. 18), and though the other embryo was attached to the uterine epithelium, it was not encompassed by it and was retarded in its embryonic development. The number of abnormal embryos may be greater than the actual number reported, especially in senescent females, if such implantations were not indicated by pontamine blue.

A faint thin diastase-resistant layer covered the apical end of the uterine epithelium in both young and aged animals. This layer was especially prominent when the epithelial folds were attached, closing the uterine lumen. The basal end of the epithelial cells also exhibited a similar layer separating the epithelium from the underlying stroma. (These layers probably correspond to the carbohydrate coat known to exist on most cells-Rambourg, Neutra \& Leblond, 1966.) During degradation of the uterine epithelium, embryos from young and senescent animals exhibited diastase-resistant granules and bodies at the region of uterine invasion (Pl. 2, Fig. 17). At the same time, a distinct layer of diastase-resistant material, brighter in colour than the previous layer, appeared along the basal membrane of the uterine epithelium. At $5 \frac{1}{2}$ days of pregnancy, however, the appearance and colour of this diastase-resistant layer had returned to what was earlier described as a cell coat.

\section{EXPLANATION OF PLATE 2}

All Figs show cross-sections of implanting hamster embryos in which the mesometrium is on the left except Fig. 15 (longitudinal section).

Fig. 13. Blastocyst which has just been enclosed by the uterine epithelium from a young hamster at $3 \frac{1}{2}$ days of pregnancy. Decidual cells are beginning to form antimesometrially. Tiny particles of glycogen are discernible in the blastocyst. $\times 380$.

Fig. 14. Blastocyst from a senescent hamster at 4 days of pregnancy. The inner cell mass, only partly visible, is not yet correctly positioned at the mesometrial side of the uterus. $\times 380$.

Fig. 15. Blastocyst from a senescent hamster pregnant for 4 days. Glycogen is not visible using the PAS technique in decidual cells of aged hamsters at this time of pregnancy. $\times 380$.

FIG. 16. Blastocyst from a senescent hamster at $4 \frac{1}{2}$ days of pregnancy. Small deposits of glycogen (arrows) are forming in decidual cells adjacent to the uterine epithelium. $\times 380$.

Fig. 17. Implanting embryo of a young hamster pregnant for $4 \frac{1}{2}$ days. The uterine epithelium is beginning to disappear as diastase-resistant granules and bodies (arrow) appear where the epithelium was located. Small deposits of glycogen are noticeable in surrounding decidual cells, but larger deposits have already formed some distance from the implantation and are not visible in the photograph. $\times 400$.

FIG. 18. Degenerating blastocyst from a senescent hamster at 5 days of pregnancy. Some decidual cells containing small deposits of glycogen have formed antimesometrially. $\times 320$. 


\section{DISCUSSION}

Thomson \& Brinster (1966), in a histochemical study of glycogen distribution in various stages of early mouse embryos, found an increasing concentration of PAS-positive material from the one-cell stage to the morula stage. Once the blastocyst had formed, there was a decrease in the intensity of the PAS reaction. The authors attributed this decrease to glycogen utilization before implantation. McReynolds \& Hadek (1972), employing the same techniques as Thomson \& Brinster for preimplantation hamster embryos, described a PAS-positive reaction which was similar in intensity for all stages examined, including the blastocyst stage.

The results of the present study are not consistent with either of the above studies. Although an intense PAS-positive reaction occurred in the one-cell hamster embryo, this intensity decreased with subsequent cellular divisions until only a very faint reaction was evident in late blastocysts. This was true for preimplantation embryos from young and senescent hamsters. Even though the embryos from aged animals were developmentally delayed, by approximately $12 \mathrm{hr}$, the staining intensity was similar at comparable stages of development.

Biochemical studies utilizing methods for the enzymatic determination of glycogen in mouse embryos indicate little change in the total concentration of glycogen from early cleavage to the late blastocyst stage (Stern \& Biggers, 1968; Ozias \& Weitlauf, 1971). Ozias \& Weitlauf (1971) have suggested that the decreased intensity of the PAS reaction noted by Thomson \& Brinster (1966) may be a result of the decreased opacity of whole mounted mouse blastocysts as they enlarge and their blastomeres become thinner. The results of the present study support this suggestion since the intensity of the PAS reaction decreased with subsequent cellular divisions. In addition, whole embryos could not be microphotometrically quantified until presumably the blastocyst cavity had formed, allowing greater transmittance of light.

\section{EXPLANATION OF PLATE 3}

All Figs show cross-sections of implanted hamster embryos. In Figs 19, 21 and 23, the mesometrium is on the right while in Figs 20, 22 and 24, the mesometrium is on the left. Frg. 19. Implanting embryo from a senescent hamster at 5 days of pregnancy. Deposits of glycogen, small in size and faint in colour, are starting to form antimesometrially, but they are not readily visible in the photograph. $\times 120$.

Fig. 20. Embryo from a young hamster at 5 days of pregnancy. Large, dense deposits of glycogen $(G)$ have completely encompassed the implantation site. $\times 120$.

FIG. 21. Implanting embryo from a senescent hamster at $5 \frac{1}{2}$ days of pregnancy. Glycogen (arrows) is starting to form, although it is considerably less than the amount found in young hamsters at this stage of embryonic development. Blood lacunae (L) are increasing in number around the implantation. $\times 120$.

Fig. 22. Embryo from a senescent hamster pregnant for $5 \frac{1}{2}$ days. Glycogen is not visible in the implantation or the surrounding decidua. There are few blood lacunae located between decidual cells in comparison to the lacunae forming at the implantation site in Fig. 21. $\times 120$.

Fig. 23. Implantation site from a young female at $5 \frac{1}{2}$ days of pregnancy. Glycogen (G) is located throughout the decidua, although deposits directly adjacent to the embryo have already disappeared. Note the extensive blood lacunae. $\times 48$.

Fic. 24. Embryo from a young hamster pregnant for $5 \frac{1}{2}$ days. A band of glycogen is present some distance from the implanted embryo. $\times 48$. 

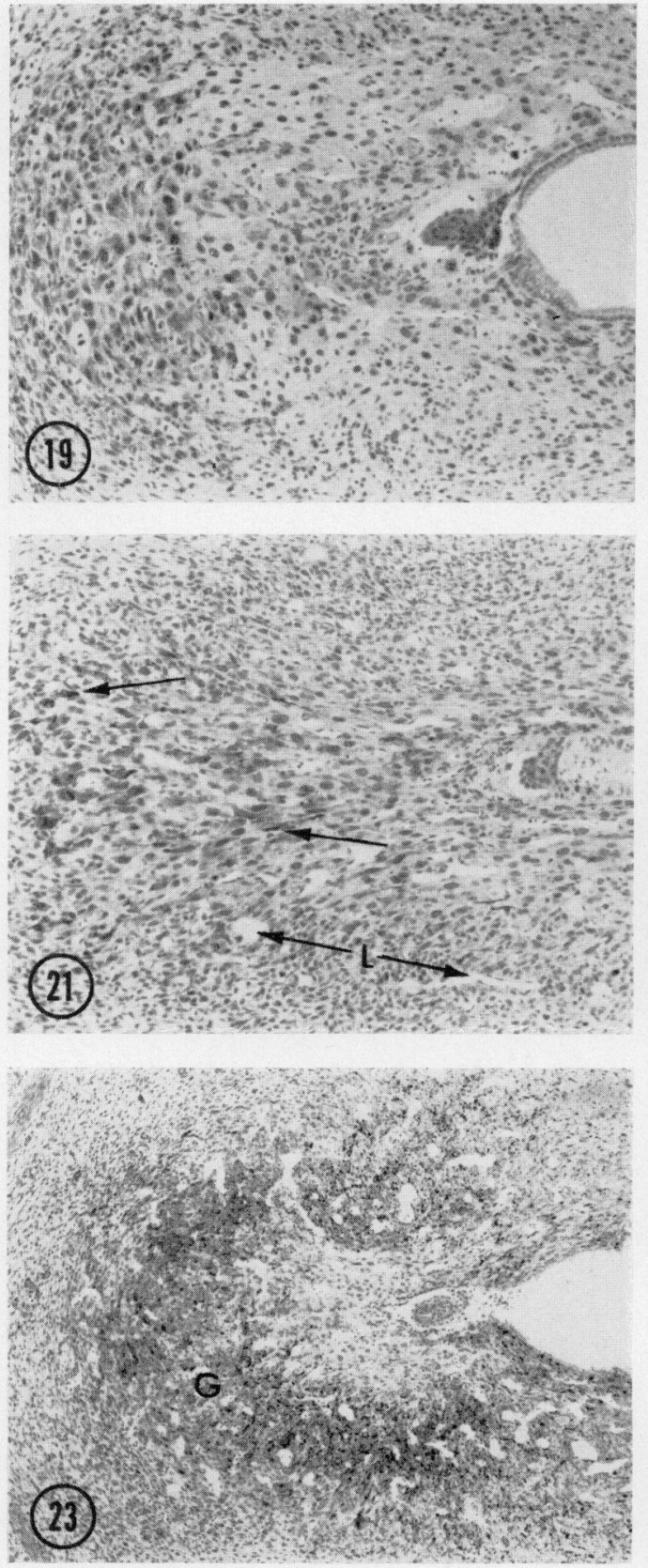
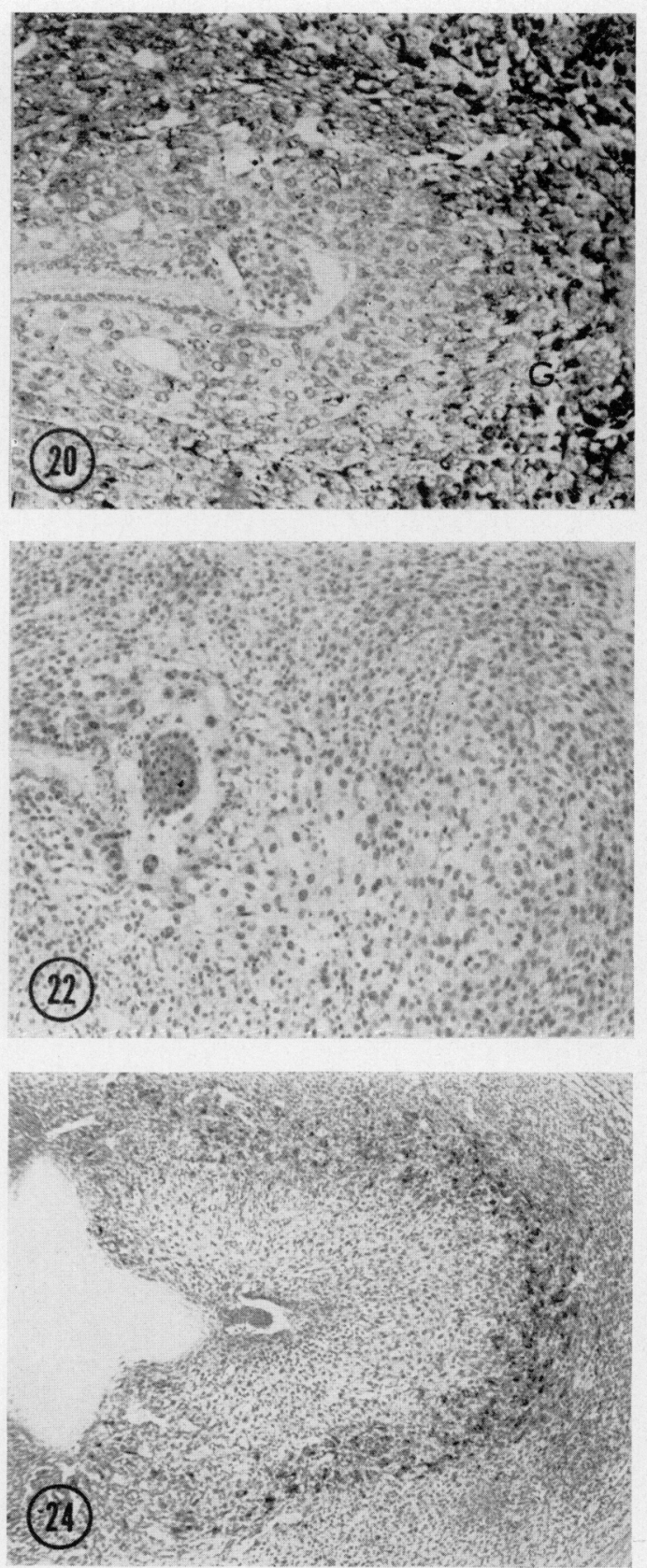
The appearance and distribution of glycogen in the young hamster uterus from Day $3 \frac{1}{2}$ to Day $5 \frac{1}{2}$ of pregnancy was essentially the same as that previously described for hamsters (Connors, 1969) and mice (Smith, 1966). The distribution was also similar to that described (Christie, 1966) in the pregnant rat uterus from Day 5 to Day 7. Christie (1966) suggested that the gradual disappearance of glycogen within the expanding rat decidua was a result of its utilization as a nutritional source. He surmised that glycogen immediately adjacent to the embryo was broken down into glucose and transported to the implantation area by the decidual blood vessels. In a further study of the rat (Christie, 1967) and in a histochemical study of implantation in the mouse (Wong \& Dickson, 1969), the disappearance of glycogen during early pregnancy was thought to be due to increased cellular divisions within the decidua, and it was suggested that the embryo was probably supported by circulating blood glucose. Christie (1967) also suggested that glycogen, once broken down, may be utilized in the synthesis and passage of protein to the embryo.

In the senescent hamster, the high incidence of non-viable ova, the developmental delay of the embryo, and the delayed appearance and intensity of the pontamine blue reaction were similar to that previously described (Parkening \& Soderwall, 1973a, b). During implantation, the general pattern of glycogen distribution in the aged animal followed the same delay, being approximately $12 \mathrm{hr}$ behind that of the young animal. The exception to this pattern was the

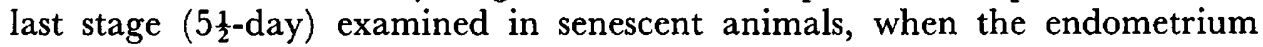
from all implantations contained noticeably less glycogen, with some embryos and their decidual cells completely lacking glycogen. At this stage, the embryo is still nutritionally dependent upon histiotrophic activity for its survival. If glycogen immediately surrounding the embryo is an available source of glucose for the embryo, its decline or absence could result in embryonic death. Thorneycroft \& Soderwall (1969) found almost twice as many resorbing implantations in senescent hamsters as in young hamsters between Day 8 and Day 15 of pregnancy. The causes for the increased resorptions are not known, but Larson $\&$ Foote (1972) found a reduction in the rate of uterine blood flow in aged rabbits, and suggested this might be one factor responsible for the reduction of litter size in older does. If circulating glucose is the major source of nourishment for the newly implanted embryo, a reduction in uterine blood flow could also have a detrimental effect. The pontamine blue reaction suggests an impairment of blood flow in the uterus of aged hamsters, although the majority of implantations in senescent hamsters at Day $5 \frac{1}{2}$ exhibited blood lacunae similar to those found in younger embryos at Day 5. Two embryos, however, which did not exhibit any glycogen, had few blood lacunae within their decidua.

There is some evidence that the aged uterus may be less sensitive to circulating hormones. Uteri of young rabbits take up four times more $\left[17-{ }^{3} \mathrm{H}\right]$ progesterone in vitro than the uteri of aged rabbits (Larson, Spilman \& Foote, 1972). If the number of uterine sites for binding progesterone were similar in both groups of animals, this would indicate that the uterus of the senescent doe was refractory to circulating progesterone. Progesterone is essential to pregnancy through the maintenance of the decidua (Deanesly, 1972, 1973), which is probably initiated and maintained by the action of progesterone on the uptake and 
utilization of glucose (Yochim, 1971). If the uteri of aged hamsters are incapable of binding sufficient quantities of circulating progesterone, only enough glucose may be utilized to initiate decidualization, but not to maintain it. A reduction in uterine circulation would have an additive effect on this condition.

Although embryos from senescent hamsters exhibit approximately a 12-hr delay in their ability to implant, the absence of glycogen would not appear to be a limiting factor in their early maintenance and survival. Once implantation has occurred, however, the decrease of glycogen noted in decidual cells, as well as the complete absence of glycogen surrounding some embryos, combined with a possible reduction in uterine blood flow, may account for the increased resorption rate noted in aged hamsters by Thorneycroft \& Soderwall (1969).

\section{ACKNOWLEDGMENTS}

This investigation was supported in part by USPHS Grant No. HD-04234-03 and by NIH Physiology Training Grant No. 5 T0I GM00336.

\section{REFERENCES}

Bulmer, D. (1959) Dimedone as an aldehyde blocking reagent to facilitate the histochemical demonstration of glycogen. Stain Technol. 34, 95.

Ghristie, G. A. (1966) Implantation of the rat embryo: glycogen and alkaline phosphatases. 7 . Reprod. Fert. 12, 279.

ChristiE, G. A. (1967) Histochemistry of implantation in the rabbit. Histochemie, 9, 13.

Connors, T. J. (1969) Reproductive senescence in the golden hamster: early development and implantation of the blastocyst. Ph.D. thesis, University of Oregon.

Connors, T. J., ThORPe, L. W. \& Soderwall, A. L. (1972) An analysis of preimplantation embryonic death in senescent golden hamsters. Biol. Reprod. 6, 131.

DeANESLY, R. (1972) Retarded embryonic development and pregnancy termination in ovariectomized guinea-pigs: progesterone deficiency and decidual collapse. F. Reprod. Fert. 28, 241.

DEANESLY, R. (1973) Termination of early pregnancy in rats after ovariectomy is due to immediate collapse of the progesterone-dependent decidua. F. Reprod. Fert. 35, 183.

FEDer, N. \& O'Brien, T. P. (1968) Plant microtechnique: some principles and new methods. Am. J. Bot. 55, 123.

Harvey, E. B., Yanagimachi, R. \& Chang, M. C. (1961) Onset of estrus and ovulation in the golden hamster. 7. exp. Zool. 146, 231.

Larson, L. L. \& Foote, R. H. (1972) Uterine blood flow in young and aged rabbits. Proc. Soc. exp. Biol. Med. 141, 67.

Larson, L. L., Spilman, C. H. \& Foote, R. H. (1972) Uterine uptake of progesterone and estradiol in young and aged rabbits. Proc. Soc. exp. Biol. Med. 141, 463.

McReynolds, H. D. \& Hadek, R. (1972) Periodic acid Schiff-positive material in hamster preimplantation embryos. F. Reprod. Fert. 30, 173.

Orsins, M. W. (1963) Morphological evidence on the intrauterine career of the ovum. In Delayed Implantation, pp. 155-166. Ed. A. C. Enders. University of Chicago Press.

Ozias, C. B. \& Weitlauf, H. M. (1971) Hormonal influences on the glycogen content of normal and delayed implanting mouse blastocysts. F. exp. Zool. 177, 147.

Parkening, T. A. \& Soderwall, A. L. (1973a) Delayed embryonic development and implantation in senescent golden hamsters. Biol. Reprod. 8, 427.

Parkening, T. A. \& Soderwall, A. L. (1973b) Preimplantation stages from young and senescent golden hamsters: presence of succinic dehydrogenase and non-viable ova. F. Reprod. Fert. 35, 373.

Pearse, A. G. E. (1968) Histochemistry, Theoretical and Applied, 3rd edn. Little, Brown and Co., Boston.

Rambourg, A., Neutra, M. \& Leblond, C. P. (1966) Presence of a "cell coat" rich in carbohydrate at the surface of cells in the rat. Anat. Rec. 154, 41 .

RuddelL, C. L. (1967) Embedding media for 1-2 micron sectioning 2. Hydroxyethyl methacrylate combined with 2-butoxyethanol. Stain Technol. 42, 253.

SMrTH, L. J. (1966) Metrial gland and other glycogen-containing cells in the mouse uterus following mating and through implantation of the embryo. Am. F. Anat. 119, 15. 
SMrTh, M. S. R. \& WrLson, I. B. (1971) Histochemical observations on early implantation in the mouse. 7. Embryol. exp. Morph. 25, 165.

Soderwall, A. L., Kent, H. A., Turbyfill, C. L. \& Britenbaker, A. L. (1960) Variation in gestation length and litter size of the golden hamster, Mesocricetus auratus. F. Geront. 15, 246.

Sokal, R. R. \& Rohlf, F. J. (1969) Biometry, the Principles and Practice of Statistics in Biological Research. W. H. Freeman and Co., San Francisco.

Stern, S. \& Biggers, J. D. (1968) Enzymatic estimation of glycogen in the cleaving mouse embryo. 7. exp. Zool. 168, 61 .

Stockтon, B. A. (1972) Reproductive senescence in the golden hamster, Mesocricetus auratus Waterhouse: temporal aspects of ovulation and induction of uterine decidual cells. Ph.D. thesis, University of Oregon.

SwIFT, H. \& Rasch, E. (1956) Microphotometry with visible light. In Physical Techniques in Biological Research, Vol. III, pp. 353-400. Eds. G. Oster and A. W. Pollister. Academic Press, New York.

Thomson, J. L. \& Brinster, R. L. (1966) Glycogen content of preimplantation mouse embryos. Anat. Rec. 155, 97.

Thorneycroft, I. H. \& Soderwall, A. L. (1969) The nature of the litter size loss in senescent hamsters. Anat. Rec. 165, 343.

Wong, Y. G. \& Dickson, A. D. (1969) A histochemical study of ovo-implantation in the mouse. $\mathcal{F}$. Anat. 105, 547.

Yоснім, J. M. (1971) Intrauterine oxygen tension and metabolism of the endometrium during the preimplantation period. In The Biology of the Blastocyst, pp. 363-382. Ed. R. J. Blandau. University of Chicago Press. 